\title{
Copper and Human Health- A Review
}

- - - - - - - - - - - - - - - Nasim Karim ---------------ABSTRACT:

Copper $(\mathrm{Cu})$, is an essential trace element. Along with lead, arsenic, mercury, cadmium etc. it is classified as a member of heavy metal group. Deficiency of copper is involved in the etiology and promotion of many disease processes related to gastrointestinal and neurological systems as well as affect functions of heart, blood vessel, pancreas etc. Deficiency of copper in early part of gestation can produce major organ malformations in the developing fetus and this in turn if persistently present can lead to neurological as well as immunological abnormalities in the newborn. Conversely presence of enormous concentrations of copper is also a great danger for the human health. Acute copper toxicity predisposes to various pathological conditions and can cause death in severe cases. Chronic exposure to copper produces anemia, liver toxicity and severe neurological defects.

Key words: Copper, Essential trace element, Heavy metal, Deficiency, Health hazards

\section{INTRODUCTION:}

Heavy metals like lead, arsenic, mercury, cadmium, copper etc. are environmental pollutants and are vastly used in industries. These metals have become a major cause of diseases in human beings ${ }^{1}$. The word Copper $(\mathrm{Cu})$ has been derived from roman word "cyprium" probably because of the presence of a large number of copper mines in Cyprus. Copper is a red colored natural metal dispersed in the whole environment surrounding us. The crust around the earth has nearly fifty parts of copper per million parts of soil (ppm). It is an important and necessary metal for all living beings inclusive of plants, animals and mankind but only if consumed at lower levels. Toxic effects are liable to occur at high levels. Copper sulfate is the most commonly used form of copper compound. Copper is usually utilized as a metal but it's alloys are also available for example brass and bronze etc. It is used in the manufacture of wires, metal sheets, pipes and other products of metals. In agriculture copper compounds are used to treat various plant diseases. They are also used for water treatment and as preservatives for wood, leather, fabrics etc $^{2}$.

Copper belongs to Group I-B of the periodic table. There are 04 different forms of copper, $\mathrm{Cu}(\mathrm{O}), \mathrm{Cu}$ (I), $\mathrm{Cu}$ (II), and $\mathrm{Cu}$ (III). Prolong exposure to copper can produce allergic rhinitis, lacrimation, photophobia and excessive salivation. Various central nervous system, gastrointestinal and renal problems can arise due to copper. Production of copper in industries produces fumes, dust particles and mists and can promote nasal mucosal atrophy. Prolong exposure to copper in high doses may cause Wilson's disease characterized by development of Kayser-fleischer ring due to corneal accumulation of copper. ${ }^{3}$

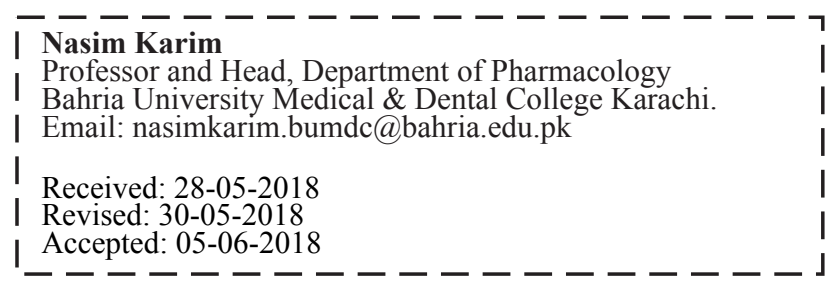

The environment around us that is water, air, soil and even food may have heavy metal contaminants including that of copper. It is the contact of these agents with the human beings that is important ${ }^{4}$. Environmental pollutants enter human body through respiratory tract, skin contact and ingestion via mouth etc ${ }^{5}$. Humans are exposed to copper mainly by consumption of contaminated food and drinking water. Copper pipes can be an important source of water contamination. Agriculture lands near the industries and highways, foods rich in copper like seafood, mushroom, seeds, nuts, pulses, dried fruit, goat cheese, fermented soy foods are other sources of exposures ${ }^{6}$.

\section{METHODOLOGY:}

Literature search was done utilizing search engines of Google and Google Scholar. Filter used are literature search duration 1997-2018, human studies, review article, original articles, guidelines. Key words and phrases used are copper trace element, heavy metal copper, pharmacokinetics of copper, pharmacodynamics of copper, biological effect of copper deficiency, health hazards of copper, analytical techniques for copper evaluation in humans. A total of 56 articles are selected for write up of this review.

\section{LITERATURE REVIEW:}

Copper $(\mathrm{Cu})$, is an essential trace element. Along with lead arsenic, mercury, cadmium etc. it is classified as a member of heavy metal group. Deficiency of copper and conversely presence of excessive amounts in the body both situations are detrimental for human health. Acute toxicity of copper predisposes to various pathological conditions and can cause death in severe cases. Chronic exposure to copper produces hepatotoxicity and neurological problems. Most of the copper compounds vividly bind to dust particles or they may be embedded in mineral component of rocks and soil. Copper gains entrance into the human body through drinking water or through respiratory tract upon inhaling dust particles that contains copper. Copper can also affect human beings in an indirect manner by dissolving in water. This soluble form of copper in water may be used in cultivation of plants or 
for rearing cattle and other animals and is really threatening our health. Upon release into lakes and rivers soluble copper compounds becomes attached to particles in water, approximately in one day and remain suspended for prolonged periods of time. The concentration of copper in air ranges from a few nanograms in a cubic meter of air $\left(\mathrm{ng} / \mathrm{m}^{3}\right)$ to about $200 \mathrm{ng} / \mathrm{m}^{3}$. This concentration may reach upto 5,000 $\mathrm{ng} / \mathrm{m}^{3}$ in the vicinity of copper smelter industries. People residing or working near mines of copper or industries that use copper metal are exposed to increased amounts of copper in the form of copper dust. The average concentration of copper in tap water ranges from 20 to $75 \mathrm{ppb}$. However, many households have copper concentrations of over 1,000 ppb. When water sits in the pipes overnight the copper present in pipes dissolves in water and thus makes this drinking water polluted for use. We can reduce the concentration of copper by letting water flow for about fifteen to thirty seconds from the tap before using it for any purpose. Copper concentration in lake water and river water varies from 0.5 to 1,000 . Copper present in gardening products for treating diseases in plants is still another source of predisposition for humans. They may come in contact with skin and may be swallowed accidentally. Soil generally contains 2 to $250 \mathrm{ppm}$ copper however up to $17,000 \mathrm{ppm}$ have been found near copper and brass industries. Copper dust and waste from copper smelters, grinding, welding and mining industries as well as sludge from sewage treatment plants accounts for high concentrations of copper in the soil around the industrial areas thereby affecting people living in the locality. Workers in these industries are exposed to copper by either inhaling dust contaminated with copper or by absorption of copper from epidermal layer of skin. Air borne exposure to copper at workplace must be regulated to reduce harmful effects to humans?

\section{Pharmacokinetics of Copper}

Absorption of copper occurs from stomach and upper intestine. It varies from $15-97 \%$ and depends upon the component of copper present in the consumed dietary amount ${ }^{8}$. Zinc and cadmium inhibit absorption of copper presumably by competitively affecting the transport of copper or by increasing the level of metallothionein in the intestines. Conversely bioavailability of copper is reduced by fructose and other carbohydrates, dietary cellulose fiber and phytates 9 . Copper binds to albumin, glutathione, and amino acids in the portal blood after being released from intestinal cells into the serosal capillaries. In the liver, copper is either incorporated into copper dependent proteins or is excreted into the bile ${ }^{10}$. Liver regulates copper release and maintains homeostatic control on the extrahepatic distribution of copper ${ }^{11,12}$. More than $95 \%$ of the copper found in plasma is present in a serum ferroxidase called as Ceruloplasmin. This sialoglycosylated oxidase protein contains 07 atoms of copper. Ceruloplasmin activates mobilizable stores of iron present in the specific cells and bring about the release of iron ${ }^{13}$. Copper is mainly eliminated through bile and is responsible for most of the component of copper present in the feces. The remaining component is obtained from copper which is either not absorbed or is obtained from the desquamation of mucosal lining cells. Copper transportation through hepatobiliary tract follows a saturable kinetics pattern. This is evident from the fact that copper elimination in the bile does not increments proportionately with the dose following intravenous administration ${ }^{14}$.

\section{Pharmacodynamics of Copper}

Copper play an important role in many oxidative processes in the human body such as produced by oxidases, cytochrome oxidase, metalloenzymes etc. In case of copper deficiency the function of these enzymes becomes erratic and thus may cause various diseases specially anemia ${ }^{15,16}$. Copper may also produce glucose -6-phosphate deficiency and hence a high risk of hematologic diseases ${ }^{17}$. Copper forms metalloprotein that is metallothionein and cytosolic copper chaperons. It activates copper-binding proteins in small peptides like albumin, ceruloplasmin, glutathione ${ }^{18}$. Copper undergoes entero-hepatic circulation and is excreted primarily in bile. It acts as catalyst in metabolic reactions and predisposes to mutations ${ }^{19,20,21}$. The copper/ zinc superoxide dismutase enzyme found in the brain, blood, liver, lung, and thyroid is responsible for provision of protection against oxygen toxicity ${ }^{22,23}$.

Copper toxicity is dependent on the ability of copper ions present in free form to catalyze the formation of reactive oxygen species such as superoxide and hydroxyl ions. Functioning of hepatic cytochrome P450 enzyme system is affected by copper ions. These ions bind and oxidize the cysteinyl containing residues of monooxygenase enzymes which are components of CYP450 system ${ }^{24}$. Increase in the levels of copper causes oxidative damage and alterations in the function of cell membranes, peroxidation of lipids, inhibition of receptors, abnormalities in liver functions, decline in fluidity, changes in the enzymes function and ionic permeation ${ }^{25}$. The dietary allowance of copper varies according to age, pregnancy, lactation, and for adults ${ }^{26,27}$.

\section{In born errors of Copper metabolism}

(1) Menkes Disease: John Menkes a physician in 1962 described this disorder for the first time. It is an X-linked syndrome that has a frequency of about $1 / 200,000$ live births. Boys are affected primarily by this disease but few girls have also been documented to be affected ${ }^{28}$. There is severe deficiency of copper which causes death in early years of childhood. Development and growth of brain requires certain enzymes which need copper for proper functioning and deficiency of copper is hence accompanied by severe neurological abnormalities. There is hypo-pigmentation of hairs due to lack of melanin being caused by deficiency of enzyme tyrosinase. Deficiency of cuproenzyme is also present so cross-linking of keratin does not occurs and the 
hair appear steely, brittle and kinky therefore also named as "kinky hair disease." The activity of cytochrome $c$ oxidase enzyme is suppressed which causes severe neurological defects including mental retardation. Death commonly occurs in children before they reach the age of ten years. Diagnosis at an initial stage and prompt management of these individuals usually fails to defer or delay death. Absorption of copper does occurs from small intestine but there is fault in pumping out of absorbed copper into the vascular tree, liver and to other parts and organs ${ }^{29,30}$.

(2) Wilson Disease: It is also named as hepatolenticular degeneration. It is an autosomal recessive inherited disorder of copper transport that involves chromosome $13^{31,32}$. It is characterized by poor copper inclusion into ceruloplasmin and impaired elimination of copper in the bile. There are mutations in the enzyme Wilson copper ATPase which in turn produces alteration in the function of this enzyme. The resultant accumulation of large amounts of copper in the liver and brain causes dysfunction of these organs. Other organs like kidneys, eyes etc. are compromised to a lesser extent. The estimated incidence of Wilson disease is $1 / 30,000^{33}$. The age on onset is 3 to 50 year. Patients with Wilson disease may present commonly with features related to hepatic, neurologic, or psychiatric problems. Hepatic features may be similar to acute hepatitis. They may be self limiting or can progress rapidly to fulminant hepatitis. Conversely picture may be of chronic active hepatitis or cirrhosis with hepatic insufficiency. Deepening jaundice, encephalopathy, clotting abnormalities, intravascular coagulation, hemolytic anemia and renal insufficiency may also be present. Death occurs in untreated cases. Copper accumulates in the liver cells, which undergo lysis if capacity is exceeded thereby releasing the metal into the circulation and promoting accumulation in the tissues other than liver. Damage is mainly produced in the region of lenticular nucleus comprising of putamen and globus pallidus and is exhibited as neurological features. This is characterized by tremors particularly in arms and hands, dyskinesias and behavioral alterations. Copper deposition at the outer rim of the iris produces characteristic rusty brown rings in the eyes called as the Kayser-Fleischer rings. Ninety percent of patients with Wilson disease develop such rings ${ }^{34}$.

(3) Other Copper-Related Hereditary Syndromes: Indian childhood cirrhosis (ICC) and idiopathic copper toxicosis (ICT), or non-Indian childhood cirrhosis are the other copper related hereditary syndromes ${ }^{35}$. Both syndromes have genetic predisposition and increased copper levels. In cases of ICC excessive copper ingestion is caused by heating or storing milk in copper or brass containers. In ICT excessive amount of copper is present in the drinking water supplies and is the causative agent that in turn produces elevated copper levels in the patients ${ }^{36}$.

\section{Biological effects of copper}

It is reported that ingestion of copper salts $20-70$ gm intent- ionally or accidentally produces features as headache, dizziness, abdominal pain, nausea, vomiting, diarrhea, increased heart rate, difficulties in respiratory process, hemolytic type of anemia, presence of blood in urine, moderate to severe GIT bleeding, hepatic and renal failure and death. Acute Exposure can occur after single or repeated intake of drinking water containing copper usually above 3-6 mg/L. It produces predominantly features of acute gastrointestinal upset such as nausea, vomiting stomach irritation. Allergic features may develop in sensitive individuals upon dermal exposure. High copper level in air produces elevated serum copper levels and hepatomegaly in workers of mining and smelting industries. Copper -T and multiload are used as intrauterine devices to prevent conception. It act by producing metal toxicity to sperm and inhibits implantation of blastocyst in the uterine endometrium as well as by inhibiting embryonic development. It has been documented that chances of spontaneous abortions are quite high in untreated females having Wilson disease ${ }^{37}$ Chronic deficiency of copper in infants and children produces features related to low $\mathrm{RBC}$ and $\mathrm{WBC}$ count. It also produces abnormalities of bone-marrow which subsides with supplements of copper. Copper is essentially involved in the synthesis and maturation of bone tissue, blood cells and also takes part in the neurological development. It also plays a vital role in the functions of cardiovascular and immune systems besides being involved in the process of lipid metabolism. Copper deficiency is commonly seen in babies and infants having low weight at birth and in children administered nutrition through parenteral route. Hypochromic, normocytic or macrocytic anemia with low copper plasma levels is produced. It is refractory to iron therapy and is readily reversed by copper supplements. There is defect in iron mobilization caused by decreased ceruloplasmin - ferroxidase I activity. Bone abnormalities are produced in low-birthweight infants and young children that are similar to scurvy. Alterations in clotting factors, bone metabolism markers, ${ }^{38}$ oxidant status, enhanced chances of infections, hypopigmentation of hair, osteoporosis, fractures of bone, abnormal bone growth etc. may also be produced. Besides genetically sensitive populations infants with low weight at birth and on cow's milk feed, pregnant and nursing women, patients on nutritional therapy through parenteral route, patients having malabsorption problems and chronic diseases, diabetics, alcoholics, elderly, athletes ${ }^{39,40}$. vegetarians and persons with eating disorders are also susceptible to develop copper deficiency ${ }^{41}$.

\section{Analytical technique}

Deficiency as well as elevated level of copper both increases risk to human health ${ }^{42}$. Copper is present in blood, urine, feces, hair, and nails. Copper level can be measured in these samples by specific tests which are not available usually at the commercial laboratories as they require special equipment. Research related to human health requires monitoring of 
metals in all biological matrices ${ }^{43}$. Samples are dissolved and pretreated for both organic and inorganic matrices prior to instrumental analysis. Spectrophotometry for determination of metals is one of the most important tools in chemical analysis of metals in biological samples ${ }^{44}$. Determination of metal levels by atomic absorption spectrometry (AAS) as mentioned above similarly requires a preliminary sample treatment ${ }^{45,46}$. In AAS sample preparation involve digestion, extraction and calibration by Certified Reference Material (CRMs) of analytes. Conventional sample preparation of organic materials for atomic absorption spectrometric analysis involves solubulization and or decomposition of the matrix typically achieved by wet digestion or dry ashing techniques using oxidative acids ${ }^{47}$. To estimate human exposure to contaminants and their concentrations, blood is generally used as a biomarker ${ }^{48,49,50,51}$.

Thus copper is essential to human health. Along with amino acids, fatty acids and vitamins it is also needed for normal reactions of metabolism taking place in our body. Copper is not synthesized by humans therefore dietary sources must supply this element. Adult body contains $1.4-2.1 \mathrm{mg}$ of copper/ kg body weight. In the body copper activates enzymes that act as catalysts. Apart from biochemical reactions copper also provides help in the transformation of, development of and elastin tissues cross-linkages, maintenance and repairing of connective tissues ${ }^{52}$.

Copper is also documented to be important for cardiovascular system and its deficiency predisposes to increased risk of developing coronary heart disease. Excess amount of copper in the body can be removed by utilizing specific chelating agents. Conversely using zinc in large amounts is also said to be beneficial. Brazilian nuts and cashew nuts, poppy and sunflower seeds, chickpeas, liver oysters, cereals, beef , mutton, fish etc are potential dietary sources of copper. Copper is also said to have anti-inflammatory, anti-ulcer and anticonvulsive properties. Diet must provide adequate amount of copper needed for the physiological processes of the body. Overall trend of changes in the human dietary patterns may result in inadequate copper intakes. Copper is also required for normal and healthy growth of plants and animals and this in turn can be beneficial to the humans through the food chains ${ }^{53}$. Toxic effect of copper is produced by its ability to incorporate and release electrons. This causes production of reactive radical ions like. Copper is said to be toxic when it is un-sequestered and un-mediated. This ultimately produces oxidative stress that plays an important role in various disease processes such as in which copper and zinc binds to. Excess level of copper are also associated with the effects of aging process ${ }^{5,55}$.

Copper is present in human body and this provides the proof that it is essential for human beings. Diet devoid of copper produces adverse effects that are reversible by administration of copper supplements. Copper content in adults is 50-120 $\mathrm{mg}$. Highest concentrations of copper are found in liver and brain. Copper in liver is the main storage form however copper content in the basal ganglia of the brain takes part in the neurotransmitter metabolism. Intravenous nutrition therapy without addition of copper produces copper deficiency state that is exhibited as features of anemia, neutropenia etc within few weeks of copper deprivation in the patients ${ }^{56}$.

\section{CONCLUSION:}

Copper $(\mathrm{Cu})$, is an essential trace element. Both deficiency and elevated level of copper are detrimental for human health. Acute copper toxicity can predispose to a number of pathological conditions and even death in severe cases. Chronic exposure to copper produces anemia, liver toxicity and severe neurological defects.

\section{REFERENCES:}

1. Wilson L. Toxic metals \& detoxification. The center for Development. 2014. Availableat:drlwilson.com/articles/ TOXIC\%20METALS.htm. Accessed on 22-5-2018.

2. Stern B R, Solioz M, Krewski D, Aggett P, Ching Aw T, Baker $\mathrm{S}$ et al. Copper and human health: biochemistry, genetics, and strategies for modeling dose-response relationships. Journal of Toxicology and Environmental Health, Part B, 10:157-222, 2007. DOI: 10.1080/10937400600755911

3. Lenntech . Chemical properties of copper - Health effects of copper - Environmental effects of copper. 2014. Accessed on 23-5-2018 https://www.lenntech.com/periodic/elements /cu.htm\#ixzz5GgRtvtWN

4. Berglund M, Elinder CG, Jarup L. Humans exposure Assessment. An Introduction. 2001. WHO/SDE/OEH/01.3, 2001:1-210

5. Barakat MA. Review Article, New trends in removing heavy metals from industrial wastewater. Arabian Journal of Chemistry. 2011; 4(4): 361-77.

6. Mudgal V, Madaan N, Singh ARB, Mishra S. Effect of Toxic Metals on Human Health. The open Nutraceuticals journal. 2010; 3: 94-9.

7. Agency for Toxic Substances and Disease Registry (ATSDR). Toxicological profile for Copper. Atlanta, GA: U.S. Department of Health and Human Services, Public Health Service. 2008. CAS\#: 7440-50-8. Accessed on 23-5-2018.

8. Turnlund J R. Human whole-body copper metabolism. Am J Clin Nutr. 1998; 67: 960S-4S.

9. Wapnir R A. Copper absorption and bioavailability. Am J Clin Nutr. 1998; 67: 1054S-60S.

10. Ralph A, McArdle H J. Copper metabolism and requirements in the pregnant mother, her fetus and children. New York: 2001.International Copper Association.

11. Harris ED. Cellular copper transport and metabolism. Annu Rev Nutr. 2000; 20: 291-310.

12. Harris ED. Copper homeostasis: The role of cellular transporters. Nutr Rev 2001; 59: 281-5.

13. Hellman NE, Gitlin JD. Ceruloplasmin metabolism and function. Annu Rev Nutr 2002; 22: 439-58.

14. Turnlund JR, Scott KC, Peiffer GL, Jang AM, Keyes WR, Keen CL et al. Copper status of young men consuming a lowcopper diet. Am J Clin Nutr 1997; 65: 72-8 
15. Osredkar J, Sustar N. Copper and Zinc, Biological Role and Significance of Copper/Zinc Imbalance. Journal of Clinical Toxicology.2011; S3: 001.

16. Bamuwamye M, Ogwok P, Tumuhairwe V. Cancer and Non-cancer Risks Associated with Heavy Metal Exposures from Street Foods: Evaluation of Roasted Meats in an Urban Setting. Journal of Environment Pollution and Human Health. 2015; 3 (2)24-30. DOI: 10.12691/jephh-3-2-1

17. Singh R, Gautam N, Mishra A, Gupta R. Heavy metals and living systems: An overview. Indian J Pharmacol. 2011;43(3): 246-53. doi: 10.4103/0253-7613.81505

18. Mercer JF. The molecular basis of copper-transport diseases. Trends Mol Med. 2001; 7:64-9.

19. Hamza I, Gitlin JD Copper chaperones for cytochrome c oxidase and human disease. J Bioenerg Biomembr .2002; 34: $381-8$.

20. Gitlin JD. Wilson disease. Gastroenterology. 2003; 125: 186877.

21. Kagan H M, Li W. Lysyl oxidase: Properties, specificity, and biological roles inside and outside of the cell. Journal of Cellular Biochemistry. 2003; 88(4): 660-72. DOI: 10.1002/jcb.10413

22. Valko M, Morris H, Cronin MT. Metals, toxicity and oxidative stress. Curr Med Chem. 2005; 12: 1161-1208.

23. ValkoM, Rhodes CJ, Moncol J. Free radicals, metals and antioxidants in oxidative stress-induced cancer. Chem Biol Interact. 2006; 160: 1-40.

24. Letelier ME ,Faúndez M,Sandoval JJ , Molina-Berríos A, Cortés-Troncoso J , Aracena-Parks. Mechanisms underlying the inhibition of the cytochrome P450 system by copper ions. Journal of Applied Toxicology. 2009. https://doi.org/ 10.1002/jat.1460. Accessed on 24-5-2018

25. Ozcelik D, Ozaras R, Gurel Z, Uzun H, Aydin S. Cu-Mediated Oxidative Stress in Rat liver. Biological Trace elements Research. 2003; 96(1-3): 209-15.

26. IOM: Institute of Medicine, Food and Nutrition Boards. Dietary Reference Intakes. Washington, DC: National Academic Press. 2001; pp.1-769.

27. Handy RD. Chronic effects of copper exposure versus endocrine toxicity: Two sides of the same toxicological process? Comp Biochem Physiol Part A. 2003; 135: 25-38.

28. Kodama H, Murata Y. Molecular genetics and pathophysiology of Menkes disease. Pediatr. Int. 1999; 41: 430-5.

29. Kaler SG. Menkes disease mutations and response to early copper histidine treatment. Nat Genet. 1996; 13: 21-2.

30. Kaler SG. Metabolic and molecular bases of Menkes disease and occipital horn syndrome. Pediatr Dev Pathol. 1998; 1: 85-98.

31. Llanos RM, Mercer JF. The molecular basis of copper homeostasis and copper-related disorders. DNA Cell Biol. 2002; 21: 259-70.

32. Gitlin JD. Aceruloplasminemia. Pediatr. Res. 1998; 44: 2716.

33. IPCS - International Programme On Chemical Safety. IOMC Inter-Organization Programme For The Sound Management Of Chemicals. A cooperative agreement among UNEP, ILO, FAO, WHO, UNIDO, UNITAR and OECD. WHO. Copper No. 200, 1998.

34. Ferenci P, Caca K, Loudiano G, Mieli-Vergani G, Tanner S,
Sternlieb I et al. Diagnosis and phenotypic classification of Wilson disease. Liver.2003; 23: 139-42.

35. Wijmenga C, Muller T, Murli IS, Brunt T, Feichtinger H, Schonitzer D et al. Endemic Tyrolean infantile cirrhosis is not an allelic variant of Wilson's disease. Eur J Hum Genet. 1998; 6: 624-8.

36. Muller T, MullerW, Feichtinger H. Idiopathic copper toxicosis. Am J Clin Nutr 1998; 67: 1082S-6S.

37. Mustafa MS, Shamina AH. Five successful deliveries following 9 consecutive spontaneous abortions in a patient with Wilson disease. Aust NZ J Obstet Gynaecol. 1998; 38: 312-14.

38. Baker A, Harvey L, Majask-Newman G, Fairweather-Tait S, Flynn A, Cashman K. Effect of dietary copper intakes on biochemical markers of bone metabolism in healthy adult males. Eur J Clin Nutr 1999; 53: 408-12.

39. Araya M, McGoldrick M., Klevay LM, Strain JJ, Robson P, Nielsen $\mathrm{F}$ et al. Determination of an acute no-observedadverse-effect level (NOAEL) for copper in water. Regul Toxicol Pharmacol. 2001; 34: 137-45.

40. Araya M, Chen B, Klevay LM, Strain JJ, Johnson L, Robson $P$ et al. Confirmation of an acute no-observed-adverse-effect level (NOAEL) and low-observed-adverse-effect level (LOAEL) forcopper in bottled drinking water in a multi-site international study. Regul Toxicol Pharmacol. 2003a;38:38999.

41. Araya M, Olivares M, Pizarro F, Gonzalez M, Speisky H, Uauy R. Gastrointestinal symptoms and blood indicators ofcopper load in apparently healthy adults undergoing controlled copper exposure. Am J Clin Nutr. 2003 b ;77: 64650.

42. Janet Y, Uriu-Adams, Keen C L. Review. Copper, oxidative stress, and human health. Molecular Aspects of Medicine 2005;26(4-5): 268-98.https://doi.org/10.1016/j.mam. 2005.07.015

43. International Atomic Energy Agency (IAEA). Sampling, storage and sample preparation procedures for $\mathrm{X}$ ray fluorescence analysis of environmental materials.IAEATECDOC-950.1997.

44. Karatepe A, Soylak M, Elci L, Lett A, KarmausW, Brooks $\mathrm{KR}$ et al. Immune function biomarkers in children exposed to lead and organochlorine compounds: A cross-sectional study. Environ Health.2002; 4:1-10.

45. Jackson KM. Electro-thermal atomic absorption spectrometry and related techniques.Analytical Chemistry. 2000; 72 (12) :159R-67R.

46. Levin AD, Pribytkov VA, Rukin EM, Seregina IF. Atomicabsorption spectrometry in the elemental analysis of biological materials, Measurement techniques. 2001; 44 (6) : 660-2.

47. Bader NR. Sample Preparation for Flame Atomic Absorption Spectroscopy: An Overview. Rasayan J Chem. 2011; 4(1): 49-55.

48. Barbosa Jr F, Santos JET, Gerlach RF, Parsons PJ. A critical review of biomarkers used for monitoring human exposure to lead: advantages, limitations, and future needs. Environ Health Perspect, 2005; 113(12): 1669-74.

49. Needham LL, Calafat AM, Barr DB. Needham Uses and issues of biomonitoring. Int J Hyg Environ Health, 2007; 210: 229-38.

50. Palmer CD, Lewis Jr ME, Geraghty CM, Barbosa Jr F, Parsons. Determination of lead, cadmium and mercury in blood for 
assessment of environmental exposure: A comparison between inductively coupled plasma - mass spectrometry and atomic absorption spectrometry. Spectrochim Acta Part B At Spectrosc. 2006; 61: 980-90.

51. Apostoli P. Elements in environmental and occupational medicine.J Chromatogr B Analyt Technol Biomed Life Sci. 2002; 5;778(1-2):63-97. PMID:12376117.

52. Cypher GA. Copper and Human Health and Safety. International Copper Association Limited, 260 Madison Avenue, New York, NY 10016, USA.
53. Copper in Human Health. Technical Note TN 34, Copper Development Association, Orchard House, Mutton Lane, Potters Bar, Herts EN6 3AP, UK.

54. Brewer GJ. Iron and copper toxicity in diseases of aging, particularly atherosclerosis and Alzheimer's disease. Exp Biol Med. 2007; 232(2): 323-35.

55. Brewer GJ. Copper toxicity in the general population. Clin Neurophysiol. 2010; 121(4): 459-60.

56. Uauy R, Maass A, Araya M.Estimating risk from copper excess in human populations. The American Journal of Clinical Nutrition, 2008; 88(3): 867S 71S. doi.org/10.1093 /ajen/88.3.867S

\section{$\bullet \bullet \bullet \uparrow \bullet \bullet \bullet \bullet$}

